\title{
SAN FRANCISCO'S GOLDEN GATE: A BRIDGE BETWEEN HISTORICALLY DISTINCT COYOTE (CANIS LATRANS) POPULATIONS?
}

\author{
Benjamin N. Sacks ${ }^{1}$, Holly B. Ernest ${ }^{1,2}$, and Erin E. Boydston ${ }^{3}$
}

Key words: Canis latrans, coyote, dispersal, microsatellites, movements.

Although coyotes (Canis latrans) are wellknown for their adaptability to human-modified landscapes (Riley et al. 2003), as with any medium to large-sized carnivore, they typically avoid highly urbanized areas (Crooks 2002), preferring instead to use habitat fragments linked by vegetated corridors (Tigas et al. 2002). However, recent observations of coyotes in San Francisco indicate their willingness to traverse even the most densely urbanized terrain (Rubenstein 2003). Herein we use DNA to show, in an extreme example, that an adult male coyote caught in the northern tip of the San Francisco peninsula traversed the 2-km Golden Gate Bridge, potentially linking historically distinct coyote populations.

We extracted DNA from the blood of a coyote that was captured, radio-collared, and released in May 2003 in the Presidio of San Francisco, part of the Golden Gate National Recreation Area located south of the Golden Gate Bridge. This coyote apparently left the park within a week and was not subsequently located. We genotyped this individual at 14 autosomal (non-sex-linked) microsatellite loci that had previously been used to delimit 4 coyote populations in central California (Sacks et al. 2004). Laboratory methods are detailed in a previous publication (Sacks et al. 2004). By comparing this genotype to the 2 adjacent populations, the North Coastal Mountain population (beginning $20 \mathrm{~km}$ north of the bridge) and the South Bay Hills population $(20 \mathrm{~km}$ south of the Bridge, just south of the city), we assigned his origin to the northern population with $97.5 \%$ probability using a Bayesian modelbased approach (Pritchard et al. 2000). The population of origin was the same when all 4 central California populations were used. Next, we genotyped this male and males in the 2 adjacent populations at 2 Y-chromosome loci (MS41A, MS41B; Sundqvist et al. 2001). The genotype of this male was present in 43 of 63 males from the northern population and none of 18 males (conservatively assumed to be 1 of 18 for probability calculation) in the southern population, indicating a $92 \%$ probability of origin in the northern population based on the Y-genotype. The combined probability of assignment (Sokal and Rohlf 1995) to the northern population based on both types of marker was $99.5 \%$, making it almost certain that this coyote came from north of the Bridge.

Although it is conceivable that the coyote was transported by humans or arrived in the Presidio without having traversed the Bridge, these scenarios seem unlikely. First, the coyote had no apparent injuries and, based on tooth wear, was several years old, making it unlikely that he had been in the recent custody of a wildlife rehabilitator (a general inquiry to all known wildlife rehabilitators in the area also turned up no information). Second, he was observed in the San Francisco park at the south end of the Bridge, a likely destination for a coyote that had walked across the Bridge, but not a likely choice as a new release site for a coyote. Third, while canids are generally good swimmers, it seems implausible that a coyote could swim across the San Francisco Bay, which has extremely treacherous currents. Finally, assuming his journey was unassisted, any land route other than the Golden Gate Bridge would have required him to circumvent the San Francisco Bay-Delta Estuary and move through the South Bay Hills population

\footnotetext{
${ }^{1}$ Wildlife and Ecology Unit, Veterinary Genetics Laboratory, School of Veterinary Medicine, University of California, Davis, CA 95616.

2Department of Population Health and Reproduction, School of Veterinary Medicine, University of California, Davis, CA 95616-8744.

${ }^{3}$ USGS Western Ecological Research Center, Las Vegas Field Station, 160 N Stephanie, Henderson, NV 89014.
} 
$(>250 \mathrm{~km})$. Because no coyotes captured in the South Bay Hills population had genetic profiles indicative of a northern origin (Sacks et al. 2004), this seems especially unlikely. Coyotes were most likely absent from the peninsula north of the Bridge when the Bridge was built in 1933 and have only recently begun recolonizing the area (Hall 2000). The recent southern recolonization of this area by coyotes, their apparent willingness to cross the Bridge, and recent documentation of coyotes in more central parts of San Francisco (Rubenstein 2003) indicate the possibility of direct gene flow between north-coastal and south-coastal coyote populations, which have been historically distinct (Sacks et al. 2004). Although it has been widely recognized that human fragmentation of the landscape can impede gene flow among parts of historically continuous populations, our findings reflect an example where a human modification to the landscape may have done the opposite-namely, facilitated gene flow between historically distinct sections of a species range.

We thank Dairen Simpson for capturing the coyote in the Presidio, Daniel Heffernan and Jennifer Shulzitski for field assistance, and Sarah Brown for laboratory assistance. We also thank Karen Blejwas and an anonymous reviewer for helpful criticisms. This research was made possible by funding from the United States Geological Survey, the Presidio Trust, and the Veterinary Genetics Laboratory at University of California, Davis.

\section{Literature Cited}

Crooks, K.R. 2002. Relative sensitivities of mammalian carnivores to habitat fragmentation. Conservation Biology 16:488-502.

HaLl, D.M. 2000. Coyote recolonization and human perception in west Marin County, California. Master's thesis, San Francisco State University, San Francisco, CA.

Pritchard, J.K., M. Stevens, and P. Donnelly. 2000. Inference of population structure using multilocus genotype data. Genetics 155:945-959.

Riley, S.P.D., R.M. Sauvajot, T.K. Fuller, E.C. York, D.A. Kamradt, C. Bromley, and R.K. Wayne. 2003. Effects of urbanization and habitat fragmentation on bobcats and coyotes in southern California. Conservation Biology 17:566-576.

Rubenstein, S. 2003. Coyote makes S.F. a truly wild town. Page Al in San Francisco Chronicle, 14 November.

Sacks, B.N., S.K. Brown, and H.B. Ernest. 2004. Population structure of California coyotes corresponds to habitat-specific breaks and illuminates species history. Molecular Ecology 13:1265-1275.

SOKaL, R.R., AND FJ. RoHLF. 1995. Biometry. 3rd edition. Freeman and Co., New York.

Sundqvist, A.-K., H. Ellegren, M. Olivier, and C. Vila. 2001. Y chromosome haplotyping in Scandinavian wolves (Canis lupus) based on microsatellite markers. Molecular Ecology 10:1959-1966.

Tigas, L.A., D.H. Van Vuren, and R.M. Sauvajot. 2002. Behavioral responses of bobcats and coyotes to habitat fragmentation and corridors in an urban environment. Biological Conservation 108:299-306.

Received 3 March 2005 Accepted 22 August 2005 